\title{
Model Bermain Konstruktif untuk Meningkatkan Kecerdasan Interpersonal Anak TK
}

\author{
Muhammad Yusri Bachtiar ${ }^{\circledR}{ }^{\circledR}$, Herlina$^{1}$, Sitti Nurhidayah Ilyas ${ }^{1}$ \\ Pendidikan Guru Pendidikan Anak Usia Dini, Universitas Negeri Makassar(1) \\ DOI: $\underline{10.31004 / o b s e s i . v 6 i 4.2013}$
}

\begin{abstract}
Abstrak
Kecerdasan interpersonal anak belum banyak dikembangkan secara terstruktur dengan baik. Tujuan penelitian ini adalah untuk menerapkan kegiatan bermain konstruktif dalam meningkatkan kecerdasan interpersonal pada anak TK di Kabupaten Gowa. Rancangan penelitian ini menggunakan metode eksperimen dengan jenis penelitian Quasi eksperimen semu. Desain peneilitian yang digunakan yaitu Nonequivalent Control Group Design. Teknik pengambilan sampel pada peneltian ini menggunakan teknik simple random sampling, dengan jumlah populasi 40 anak dan junlah sampel 20 anak. Teknik pengumpulan data pada penelitian ini adalah observasi, wawancara dan dokumentasi. Analisis data yang digunakan adalah uji $t$ untuk membandingkan dua kelompok eksperimen dan kontrol. Data yang diuji menggunakan skor kecerdasan interpersonal. Hasil perhitungan uji $\mathrm{t}$ diperoleh $\mathrm{t}(\mathrm{hitung})$ $=2,178$ dengan harga $\mathrm{t}($ tabel $)=1,734 \mathrm{dan} \mathrm{dk}=18$ dengan taraf signifikan $\mathrm{a}=0.05$ sehingga ditemukan adanya perbedaan signifikan antara kedua kelompok. Hasil penelitian dapat disimpulkan bahwa anak yang bermain konstruktif dapat meningkatkan kecerdasan interpersonal anak. Kecerdasan ini dapat dikembangkan dalam pembelajaran Anak di Taman Kanak-kanak.
\end{abstract}

Kata Kunci: kecerdasan interpersonal; bermain konstruktif; anak usia dini

\begin{abstract}
Children`s interpersonal intelligence has now no longer been evolved in a well-dependent manner. The reason of this look at turned into to use positive play sports in enhancing interpersonal intelligence in kindergarten youngsters in Gowa Regency, Indonesia. This studies layout makes use of an experimental technique with a quasi-quasi-experimental sort of studies. The studies layout used is the Nonequivalent Control Group Design. The sampling approach used on this studies is straightforward random sampling, with a populace of forty youngsters and a pattern of 20 youngsters. Data series strategies on this look at have been observation, interviews and documentation. Data evaluation used t check to examine the 2 experimental and manage groups. The statistics examined the usage of interpersonal intelligence scores. The effects of the $t$ calculation received $t$ (count $)=2.178$ with a rate of $t($ table $)=1.734$ and $d k=18$ with a big level $=0.05$ in order that a big distinction turned into determined among the 2 groups. The effects of the look at may be stated that youngsters who construct can enhance kid's interpersonal intelligence. This intelligence may be evolved in kid's mastering in Kindergarten. Keywords: constructive play; interpersonal intelligence; kindergartens.
\end{abstract}

Copyright (c) 2022 Muhammad Yusri Bachtiar, et al.

$\triangle$ Corresponding author :

Email Address : m.yusri@unm.ac.id (Makassar, Indonesia)

Received 26 October 2021, Accepted 14 January 2022, Published 1 February 2022 


\section{PENDAHULUAN}

Salah satu bagian penting yang tidak bisa lepas dari kehidupan manusia adalah pendidikan. Fungsi pendidikan adalah membentuk kepribadian, keterampilan dan memahami ilmu pengetahuan. Pendidikan memiliki peran penting membentuk sebuah pribadi manusia. Hal ini menjadi fenomena penting di pemerintahan. Harapan bangsa adalah memiliki generasi baru melalui anak. Generasi penerus bangsa yang memiliki kualitas baik mampu beradaptasi untuk kehidupan bermasyarakat, berbangsa dan bernegara. Sejalan dengan itu pada Undang-Undang dasar nomor 20 tahun 2003 tentang Sistem Pendidikan Nasional memiliki tujuan untuk mengembangkan potensi peserta didik.

Putri (2012) salah satu bentuk mengembangkan sumber daya manusia berkualitas adalah hadirnya satuan lembaga Pendidikan anak usia dini yang memiliki tujyan untuk membina anak usia dini. Sejalan dengan itu Bachtiar (2016) mengemukakan bahwa pendidikan anak usia dini memiliki manfaat bagi masa depan, menyiapkan anak untuk memiliki kepribadian baik hingga dewasa. Sehingga, lembaga Pendidikan anak usia dini merupakan salah satu jenjang pendidikan yang bertujuan menstimulasi generasi bangsa. Pada Undang-Undang dasar nomor 20 tahun 2003 pendidikan anak usia dini merupakan upaya pembinaan untuk anak usia 0-6tahun yang dilakukan melalui pemberian rangsangan untuk membantu pertumbuhan dan perkembangan untuk memasuki jenjang pendidikan selanjutnya.

Menurut Herlina (2019) perkembangan anak usia dini diibaratkan sebagai pondasi sebuah rumah untuk memperkuat rumah dengan maksud sebagai pondasi untuk melanjutkan ke jenjang lebih lanjut. Santrock (2007) mengemukakan terdapat tiga aspek perkembangan yang perlu dikembangkan untuk anak usia dini yaitu; motorik, kognitif dan sosial-emosional. Sedangkan Suyanto (2003) perkembangan anak usia dini memiliki multi dan interdisipliner.

Namun fenomena yang hadir di lingkup pendidikan anak usia dini adalah fenomena calistung. Pada penelitian Dewi dan Uswatun (2021) fenomena calistung menitik beratkan kepada peserta didik dibidang akademik. Persepsi orang tua yang muncul bahwa anak memiliki perkembangan dan pertumbuhan yang baik ketika fasih dalam bidang calistung. Sejalan dengan itu menurut Nurhalimah dan Eva (2021) calistung menjadi fenomena dikarenakan ketakutan orang tua bahwa anaknya kurang pintar ketika tidak mampu calistung.

Padahal dalam Peraturan Menteri Pendidikan dan Kebudayaan nomor 146 tahun 2014 tentang kurikulum 2013 pendidikan anak usia dini terdapat empat kompetensi yaitu; sikap spiritual, sikap sosial, inti pengetahuan dan keterampilan. Sehingga akademik bukan satusatunya bagian penting dalam proses perkembangan dan pengetahuan anak. Sejalan dengan itu Santrcok (2007) mengemukakan selain motorik dan kognitif ada perkembangan sosialemosional anak.

Gardner (2020) dalam bukunya menemukan bahwa kecerdasan itu majemuk. Kecerdasan majemuk berupa kecerdasan linguistic, logika matematika, music, visual spasial, kinestetik, interpersonal, intrapersonal dan natural. Pada penelitian Ilyas (2019) esensi dari teori kecerdasan majemuk yang dimiliki Gardner adalah menghargai keistimewaan dan kemampuan peserta didik. Kecerdasan majemuk ini menjadi gambaran kemampuankemampuan apa saja yang perlu dikembangkan. Sehingga hadirnya kecerdasan majemuk mampu membuka kaca mata pendidik dan orang tuas peserta didik, kalau kecerdasan tidak hanya akademik.

Salah satu kecerdasan majemuk yang linear dengan sosial emosional peserta didik adalah kecerdasan Interpersonal. Kecerdasan Interpersonal adalah keahlian dalam mengidentifikasi perilaku, sikap, motivasi dan merespon kemauan orang lain. Serta, kemampuan interpersonal memiliki fungsi untuk merespon perbedaan-perbedaan yang mencakup dimensi sensitivitas sosial, sosial kognitif, dan komunikasi sosial juga sangat diperlukan dalam mendukung kecerdasan interpersonal Abas et al (2019). Sensitivitas sosial 
adalah kemampuan individu untuk berinteraksi dengan orang lain van Hoorn et al., (2018), Sosial kognitif ditentukan berdasarkan kondisi dimana setiap elemen sosial merasakan kepercayaan diri (Tariq et al., 2019), dan komunikasi sosial sangat penting dalam interaksi sosial dalam berbagi informasi, pikiran maupun ide dengan orang lain (Fuller \& Kaiser, 2020).

Anak yang berkembang kecerdasan interpersonalnya akan memiliki kompetensi yang berbeda-beda seperti keterampilan berkomunikasi, mediasi dan negosiasi serta kepemimpinan dalam berorganisasi. Untuk meningkatkan keterampilan komunikasi harus dirancang melalui perhatian terhadap rangsangan sosial Griffith et al., (2020). Kemampuan anak untuk dapat memahami secara efektif dan bekerja sesuai dengan tujuan. Secara khusus kemampuan anak dapat mengontrol dan menguasai pembelajaran yang bersifat sosial emosional (Rodman et al., 2019). Selain itu, (Okwuduba et al., 2021) juga mencatat bahwa Kecerdasan interpersonal adalah kemampuan individu dalam menyelesaikan masalah pada saat menghadapi proses pembelajatan di sekolah. Secara individu terdapat dua hal yang salaing berkaitan yaitu kecerdasan interpersonal dan intrapersonal. Kecerdasan interpersonal mengacu pada kemampuan anak untuk bekerja secara efektif, memahami dan mengenal tujuan (Aouani et al., 2019).

Pentingnya kecerdasan interpersonal merupakan dimensi yang memiliki tanggung jawab yang tinggi pada diri individu dalam hal beradaptasi, suasana hati dan hubungan sosial (Vaquero-Solís et al., 2020). Kecerdasan interpersonal sebagai potensi yang ada pada diri individu untuk memahami dan mengerti dan memikirkan hubungan individu yang ada disekitarnya. Peningkatan kapasitas individu dimulai dari penyesuai pendekatan terhadap potensi pribadi dan profesionalisme guru dimasa mendatang (Klieba et al., 2020). Profesionalisme guru bertanggung jawab dalam proses pembelajaran untuk mengembangkan pengetahuan kognitif, apektif dan psikomotorik anak disekolah (Amirova, 2020). Jika individu dapat diterima diantara teman sebaya maka dapat dikatakan memiliki kecerdasan interpersonal yang baik.

Pengembangan kecerdasan interpersonal mengacu pada pembelajaran sosial emosional yang terkait dengan sikap dan perilaku anak yang mengarahkan pada pikiran dan perasaan sehingga dapat memberikan kontribusi yang positif pada proses pembelajaran (Bailey et al., 2021). Sesuai dengan yang disampaikan oleh Bachtiar (2017) bahwa kecerdasan interpesonal merupakan kemampuan seseorang dalam membentuk, memahami dan mengenal perasaan orang lain agar interaksinya sesuai dengan apa yang diharapkan. Konsep kecerdasan interpersonal anak merupakan kemampuan untuk bersosialisasi, berkomunikasi, berempati dengan teman sebaya, dan mampu mengembangkan hubungan yang harmonis dengan anak lainnya. Hubungan interpersonal ini menegaskan pada Kerjasama, saling pengertian dan melakukan inisiatif sendiri dalam memulai hubungan yang harmonis (Klinkosz et al., 2021).

Guru menjadi faktor utama dalam menentukan keberhasilan anak dalam bersosialisasi dan beradaptasi pada saat anak berada sekolah (Gan, 2018; Fauziddin et al., 2021). Oleh karena itu, peran guru sangat menentukan dalam mengembangkan kecerdasan interpersonal anak dengan baik. Peran guru sebagai teladan ditunjukkan oleh tutur kata, sikap, dan kepribadiannya, seperti sopan santun, disiplin, tanggung jawab, toleransi, jujur, serta kepedulian terhadap peserta didik dan orang lain (Palunga \& Marzuki, 2017). Namun demikian peran orang tua juga menjadi faktor yang menentukan (Meilanie, 2020). Salah satu cara guru mengoptimalkan kecerdasan interpersonal anak adalah menggunakan media. Berdasarkan hasil penelitian (Agustin et al., 2021) 50\% responden menjawab cara yang optimal memperkenalkan kecerdasan interpersonal anak usia dini saat belajar dari rumah adalah menggunakan media.

Adapun aturan pasti pada Peraturan Pemerintah No.146 Tahun 2014 mengenai Kurikulum 2013 Pendidikan Anak Usia Dini bahwa terdapat prinsip-prinsip mengenai proses pembelajaran di pendidikan anak usia dini. Adapun prinsip ke 10 mengenai pedoman pembelajaran anak adalah pemanfaatan media. Sejalan dengan itu menurut Pahrul et al., 
(2019) perlunya media yang berpusat dengan kegiatan anak dalam meningkatkan kecerdasan interpersonal anak. Sehingga pentingnya menentukan media yang sesuai dengan anak usia dini, hal ini dikarenakan agar dalam proses meningkatkan kecerdasan inter personal anak lebih mudah dan optimal.

Bachtiar (2017) pada penelitiannya dalam mengembangkan kecerdasan interpersonal membutuhkan sebuah media pembelajaran agar lebih efektif. Sementara itu Damayanti et al. (2018) merekomendasikan bermain peran mikro bebas lebih cocok diterapkan dalam mengembangkan kecerdasan interpersonal. Masganti (2021) dalam bukunya mengemukakan bahwa cara yang optimal memperkenalkan kecerdasan majemuk pada anak usia dini melalui permainan teradisional. Sedangkan menurut Nikmah \& Iswantiningtyas (2020) pada publikasinya menemukan fakta bahwa kecerdasan majemuk dapat dikembangkan dengan baik menggunakan cara bermain. Hal ini dikarenakan dunia bermain merupakan dunia anak. Sehingga, ketika pembelajaran berbasis bermain anak tidak mudah bosan atau jenuh dalam pembelajaran. Pada penelitiannya Nopriyani dan Nina, (2014) menemukan terdapat peningkatan signifikan kecerdasan interpersonal dan intrapersonal melalui bermain konstruktif, namun kurang efektif dikarenakan anak diberi media sendiri-sendiri, sehingga intrapersonal yang dominan.

Pada saat anak bermain konstruktif anak juga belajar menghibur diri, bersikap sosial, bekerjasama dan menghargai prestasi teman bermainnya. (Machado et al., 2016) mengemukakan bahwa bermain konstruktif bertujuan untuk untuk menciptakan sesuatu objek menjadi bentuk yang sudah direncanakan. Bermain konstruktif didesain melalui permainan yang terjadi ketika anak-anak Agar anak memahami bagaimana mengkonstruksi atau membangun bentuk yang dikehendaki seperti apa yang pernah dilihatnya. Lebih lanjut dalam penelitian ini mengatakan bahwa aktivitas bermain konstruktif pada anak memberi ikatan yang positif dengan keterampilan matematika, melihat dan mental seorang anak pada saat melakukan permainan (Pirrone et al., 2015).

Pada penelitian ini permainan konstruktif yang dilakukan adalah permainan balok bangunan yang merupakan salah satu cara pengembangan kecerdasan visual spacial anak (Dewi, Dian Puspa, Fachrurrazi et al., 2014). Anak-anak akan diminta terlebih dahulu mengenal jenis-jenis bangunan. Setelah itu anak-anak akan dibuat menjadi beberapa kelompok untuk bekerjasama dalam membuat salah satu bangunan konstruktif yang diperlihatkan. Sebelum permainan konstruktif dilakukan pendidik memberitahu aturan permainan balok bangunan. Adapun aturan permainan yang diterapkan adalah anak-anak bebas mengambil jenis balok bangunan yang diinginkan, membuat satu jenis balok bangunan setiap kelompok, Setiap kelompok akan menceritakan produk konstruktif bangunan yang telah dibuat dan anak merapikan kembali balok bangunan

Berdasarkan uraian tersebut, peneliti merasa perlunya meingkatkan kecerdasan interpersonal anak taman kanak-kanak. Salah satu bentuk efektif dalam meningkatkan kecerdasan interpersonal anak adalah bermain konstruktif. Maka dari itu peneliti ingin melihat gambaran model bermain konstruktif untuk meningkatakn kecerdasan interpersonal anak.

\section{METODOLOGI}

Metode yang digunakan dalam penelitian ini adalah metode eksperimen dengan jenis penelitian Quasi eksperimen semu dan desain peneilitian yang digunakan yaitu Nonequivalent Control Group Design dapat digambarkan pada gambar 1 (Sugiono 2016). Terdapat dua kelas yaitu kelas kontrol dan kelas eksperimen dengan tujuan sebagai perbandingan. Kedua kelas tersebut diberikan pretest dan Postest yang bertujuan untuk mengetahui pemahaman awal kecerdasan interpersonal anak didik sebelum dan sesudah diberikan perlakuan bermain konstruktif. 


\section{Keterangan}

$\mathrm{O} 1$ dan O3

$X$

$\mathrm{O} 2$

$\mathrm{O} 4$

\begin{tabular}{|lll|}
\hline 01 & $x$ & 02 \\
03 & & 04 \\
\hline
\end{tabular}

\section{Gambar 1. Desain Penelitian}

: Pengukuran awal kecerdasan interpersonal sebelum diberikan perlakuan bermain konstruktif.

: Treatmen atau perlakuan kegiatan bermain konstruktif

: Pengukuran kedua setelah diberikan perlakuan kegiatan bermain konstruktif

: Pengukuran yang tidak diberikan perlakuan kegiatan bermain konstruktif

Adapun teknik pengumpulan data yang digunakan adalah obeservasi yang berupa test dan dokumentasi. Metode observasi adalah proses pengambilan data dalam penelitian dilakukan dengan melihat langsung dan mencatat fenomena yang terjadi terhadap subjek dan objek yang diteliti. Dokumentasi dilakukan untuk memperoleh data yang berupa dokumendokumen yang relevan dengan pelaksanaa kegiatan penelitian.

Teknik Analisis data digunakan adalah analisis statistik deskriptif dan analisis statistik inferensial. Untuk analisis deskriptif dimaksudkan untuk menggambarkan kecerdasan interpersonal anak melalui kegiatan bermain konstruktif. Selanjutnya analisis inferensial ditujukan untuk menguji hipotesis penelitian dengan mneggunakan uji normalitas, uji homogenitas dan uji t.

\section{HASIL DAN PEMBAHASAN}

Dari data pretest kecerdasan interpersonal dapat diperoleh data yang mengikuti kegiatan bermain konstruktif sebagaimana pada tabel 1 .

Tabel 1. Hasil Analisis Statistik Deskriptif Pretest Kelompok Eksperimen dan Kontrol

\begin{tabular}{ccc}
\hline $\begin{array}{c}\text { Kelompok } \\
\text { perlakuan }\end{array}$ & $\begin{array}{c}\text { Peretest kelompok } \\
\text { eksperimen }\end{array}$ & $\begin{array}{c}\text { Prestest kelompok } \\
\text { kontrol }\end{array}$ \\
\hline $\mathrm{N}$ & 10 & 10 \\
Mean & 16,3 & 14,6 \\
Median & 16,5 & 14,5 \\
Modus & 18 & 14 \\
STDV & 1,947 & 1,647 \\
Varians & 2,700 & 0,80 \\
Skor min & 12 & 12 \\
Skor Max & 18 & 18 \\
Range & 16,3 & 14,6 \\
Sum & 160 & 143 \\
\hline
\end{tabular}

Pada kegiatan bermain konstruktif terhadap kecerdasan interpersonal terdapat data yang digunakan menjadi perbandingan untuk membuktikan adanya pengaruh yang terjadi pada kecerdasan interpersonal.

Data preetest kecerdasan interpersonal pada kelompok eksperimen yang melaksanakan kegiatan bermain konstruktif

Data menunjukkan bahwa kecerdasan interpersonal pada anak mengikuti kegiatan bermain konstruktif pada interval 12-13 terdapat 1 responden dengan persentase $10 \%$, interval 
14-15 terdapat 2 responden dengan persentase 20\%, interval 16-17 terdapat 3 responden dengan persentase $30 \%$ dan interval 18-19 terdapat 4 responden dengan persentase $40 \%$ bisa dilihat pada tabel 2. Dari tabel 2 menunjukkan bahwa anak yang diberikan permainan konstruktif tanpa mengiktui langka-langkah permainan konstruktif anak belum mampu menyelesaikan permasalahan secara mandiri, menghasilkan produk dan belum bersifat perilaku yang kreatif.

Tabel 2. Distribusi Frekuensi pretest kelompok eksperimen

\begin{tabular}{ccc}
\hline Interval & Frekuensi Absolut (f) & Frekuensi Relatif \\
\hline $12-13$ & 1 & 10 \\
$14-15$ & 2 & 20 \\
$16-17$ & 3 & 30 \\
$18-19$ & 4 & 40 \\
Jumlah & 10 & 100 \\
\hline
\end{tabular}

Data pretest kecerdasan interpersonal pada kelompok kontrol yang melaksanakan kegiatan bermain

Data menunjukkan bahwa kecerdasan interpersonal pada anak mengikuti kegiatan bermain konstruktif pada interval 12-13 terdapat 2 responden dengan persentase $20 \%$, interval 14-15 terdapat 6 responden dengan persentase 60\%, interval 16-17 terdapat 1 responden dengan persentase $10 \%$ dan interval 18-19 terdapat 1 responden dengan persentas $10 \%$ bisa dilihat pada tabel 3.

Tabel 3. Distribusi Frekuensi postest Kelompok Eksperimen

\begin{tabular}{ccc}
\hline Interval & Frekuensi Absolut (f) & Frekuensi Relatif \\
\hline $12-13$ & 2 & 20 \\
$14-15$ & 6 & 60 \\
$16-17$ & 1 & 10 \\
$18-19$ & 1 & 10 \\
Jumlah & 10 & 100
\end{tabular}

Data ini menunjukkan anak yang tidak melakukan permainan konstruktif tidak meperlihatkan kemampuan dalam menyelesaikan masalah secara mandiri, belum menghasilkan produk dan belum berperilaku kreatif

Dari data postest kecerdasan interpersonal maka dapat diperoleh data yang mengikuti kegiatan bermain konstruktif sebagaimana ditunjukkan pada tabel 4 .

Tabel 4. Hasil Analisis Statistik Deskriptif Postest Kelompok Eksperimen dan Kontrol

\begin{tabular}{ccc}
\hline $\begin{array}{c}\text { Kelompok } \\
\text { perlakuan }\end{array}$ & $\begin{array}{c}\text { Postest kelompok } \\
\text { eksperimen }\end{array}$ & $\begin{array}{c}\text { Pretest kelompok } \\
\text { kontrol }\end{array}$ \\
\hline $\mathrm{N}$ & 10 & 10 \\
Mean & 18 & 16 \\
Median & 18 & 16 \\
Modus & 18 & 16 \\
STDV & 1,944 & 1,567 \\
Varians & 2,800 & 0,80 \\
Skor min & 14 & 14 \\
Skor Max & 20 & 20 \\
Range & 18 & 16,3 \\
Sum & 180 & 160 \\
\hline
\end{tabular}


Data posttest kecerdasan interpersonal pada kelompok eksperimen yang melaksanakan kegiatan bermain konstruktif

Hasil penelitian menunjukkan bahwa kecerdasan interpersonal pada anak mengikuti kegiatan bermain konstruktif pada interval 12-13 terdapat 1 responden dengan persentase 10 $\%$, interval 14-15 terdapat 2 responden dengan persentase $20 \%$, interval 16-17 terdapat 3 responden dengan persentase $30 \%$ dan interval 18-19 terdapat 4 responden dengan persentas $40 \%$ bisa dilihat pada tabel 5. Anak yang sudah melakukan Langkah-langkah bermain konstruktif sudah mampu menyelesaikan masalah secara mandiri, membuat produk secara terstruktur dan sudah mampu melakukannya secara kreatif

Tabel 5. Distribusi Frekuensi Eksperimen Kelas Eksperimen

\begin{tabular}{ccc}
\hline Interval & Frekuensi Absolut (f) & Frekuensi Relatif \\
\hline $12-13$ & 1 & 10 \\
$14-15$ & 2 & 20 \\
$16-17$ & 4 & 40 \\
$18-19$ & 3 & 30 \\
Jumlah & 10 & 100 \\
\hline
\end{tabular}

Data posttest kecerdasan interpersonal pada kelompok kontrol yang melaksanakan kegiatan bermain konstruktif

Data menunjukkan bahwa kecerdasan interpersonal pada anak mengikuti kegiatan bermain konstruktif pada interval $12-13$ terdapat 2 responden dengan persentase $20 \%$, interval 14-15 terdapat 7 responden dengan persentase $70 \%$, interval 16-17 terdapat 0 responden dengan persentase $0 \%$ dan interval 18-19 terdapat 1 responden dengan persentas $10 \%$ bisa dilihat pada tabel 6 .

Tabel 6. Distribusi Frekuensi Postest Kelompok Kontrol

\begin{tabular}{ccc}
\hline Interval & Frekuensi Absolut $(\mathrm{f})$ & Frekuensi Relatif \\
\hline $12-13$ & 2 & 20 \\
$14-15$ & 7 & 70 \\
$16-17$ & 0 & 0 \\
$18-19$ & 1 & 10 \\
Jumlah & 10 & 100 \\
\hline
\end{tabular}

Data ini menunjukkan anak yang tidak melakukan permainan konstruktif tidak meperlihatkan kemampuan dalam menyelesaikan masalah secara mandiri, belum menghasilkan produk dan belum berperilaku kreatif

Pengujian data dilakukan untuk meningkatkan kecerdasan interpersonal anak melalui kegiatan bermain konstruktif dengan menggunakan Teknik inferensial yang dimaksud untuk menguji hipotesis penelitian mengenai ada tidaknya fakta yang dapat meningkatkan kecerdasan interpersonal anak melalui kegiatan bermain konstruktif. mengetahui apakah sampel berasal dari populasi berdistribusi normal. Maka dilakukan uji normalitas dengan menggunakan uji Lilliefors. Syarat uji normalitas data yakni $\mathrm{HO}$ diterima apabila $\mathrm{L}_{\text {hitung }}<\mathrm{L}_{\text {tabel }}$ dan $\mathrm{H} 0$ ditolak apabila $\mathrm{L}_{\text {hitung }}>\mathrm{L}_{\text {tabel }}$.

Rangkuman hasil perhitungan uji normalitas kedua kelompok penelitian dapat disajikan pada tabel 7 .

Tabel 7. Uji Normalitas Kelompok Eksperimen dan Kontrol

\begin{tabular}{lcccc}
\hline \multicolumn{1}{c}{ Kelompok data } & $\mathrm{N}$ & $L_{h}$ & $L_{t(\alpha=0,05)}$ & Keteranga \\
\hline Kelompok eksperimen & 10 & 0,200 & 0,258 & Berdistribusi Normal \\
Kelompok Kontrol & 10 & 0,159 & 0,258 & Berdistribusi Normal \\
\hline
\end{tabular}


Untuk uji Homogenitas pada dua kelompok dilakukan dengan uji $F$ yakni membandingkan harga $F_{\text {tabel }}$ pada taraf signifikansi 0,05 , dengan hasil perhitungan diperoleh $F_{\text {hitung }}(1,111)$ dan $F_{\text {tabel }} \quad(3,18)$ sehingga dapat disimpulkan kedua kelompok berasala dari populasi yang homogen maka dapat dilanjutykan ke uji Hipotesis

Hasil perhitungan dengan menggunakan uji hipotesis-t diperoleh $F_{\text {hitung }}=2,178$ dengan harga $F_{\text {tabel }}=1,734$ dan harga dk $=18$ dengan taraf signifikan a $=0.05$ sehingga menunjukkan adanya perbedaan signifikan antara kedua kelompok, dimana kegiatan pembelajaran bermain konstruktif dapat meningkatkan kecerdasan interpersonal anak.

\section{Pembahasan}

Berdasarkan gambaran model bermain konstruktif untuk melihat pengaruh yang signifikan pada kecerdasan interpersonal anak pada saat proses perlakuan pada anak dapat diarahkan untuk melakukan kegiatan bermain konstruktif agar anak merasa bahagia dalam bermain ini disebabkan karena anak akan mendapatkan pengalaman langsung dan merasa bangga dalam kegiatan bermain konstruktif. Hal ini disebabkan karena kegiatan bermain konstruktif dapat mengajak anak untuk mengenal dan mengetahui berbagai hal yang terdapat pada lingkungan sekitar anak sehingga dapat melatih dan meningkatkan kecerdasan interpersonal anak. Untuk meningkatkan kecerdasan interpersonal anak maka perlu ada strategi khusus dalam bermain peran yang lebih konstruktif (Ching \& Hsu, 2016) .

Lebih lanjut dalam penelitian ini mengatakan bahwa aktivitas bermain konstruktif pada anak memberi ikatan yang positif dengan keterampilan matematika, melihat dan mental seorang anak pada saat melakukan permainan. Permainan konstruktif dapat memberikan konstribusi yang berkaitan dengan aktivitas sosial dan membantu anak untuk dapat berpikir secara kreatif maupun imajiantif karna pada saat bermain konstruktif anak berkolaborasi selama bermain (Supli et al., 2021). Kegiatan bermain konstruktif merupakan bentuk permainan yang lebih menekankan pada proses daripada hasilnya.

Pada penelitian ini juga guru dapat menjelaskan langkah-langkah kegiatan bermain konstruktif diantaranya sebelum melaksanakan kegiatan permainan, guru menyiapkan berbagai macam media peralatan bermain konstruktif, menjelaskan pada anak dalam membedakan berbagai macam bentuk-bentuk dalam bermain konstruktif dan memberikan kesempatan pada anak untuk melakukan dan mencoba membuat bentuk bangunan yang sesuai dengan objek yang dilihatnya. Wulandari \& Bachtiar (2021) menyampaikan bahwa permainan konstruktif merupakan aktivitas yang dilakukan oleh anak untuk dapat membentuk dan menciptakan hail karya tertentu sehingga dapat membangun dan menumbuhkan rasa ingin tahu, percaya diri dan dapat mengembangkan berbagai potensi yang ada pada diri anak baik itu secara fisik motorik, kognitif, bahasa dan sosial emosional.

Sesuai yang dikemukakan oleh Ubago-Jiménez et al. (2020) Kecerdasan interpersonal merupakan Kemampuan yang dimiliki seseorang dalam memahami suasana hati, perasaan, motivasi, dan berinteraksi dengan orang lain. Anak yang tinggi kecerdasan interpersonal akan lebih mudah untuk dapat bergaul, percaya diri dan mampu menyelesaikan berbagai macam masalah. Olehnya itu kecerdasan interpersonal merupakan bagian penting yang harus dimiliki oleh setiap anak sehingga anak dengan mudah keluar dari berbagai macam masalah yang dihadapinya. Dalam hal hubungannya dengan bermain konstruktif anak akan lebih mampu mengembangkan segala kemampuannya dalam berinteraksi dengan orang lain. Pahrul et al. (2019) menemukan bahwa kecerdasan interpersonal dapat dikembangkan melalui kegiatan menggambar, di mana melalui menggambar anak-anak dapat berinteraksi selain mengekspresikan emosi.

Kegiatan bermain konstruktif dapat memberikan rangsangan pada perkembangan kecerdasan interpersonal pada anak, olehnya itu guru perlu memberi stimulus kepada anak dalam melaksanakan kegiatan bermain konstruktif dalam proses belajar mengajar disekolah agar anak didik mendapat kesempatan untuk melakukan interaksi dan berkomunikasi serta 
mengenal lingkungan sosial. Kecerdasan interpersonal harus dimiliki oleh anak sejak usia dini, karena anak usia dini merupakan makhluk sosial. Dengan demikian dapat diketahui bahwa ada beberapa hal yang dapat menyebabkan perbedaan antara kemampuan kecerdasan interpersonal anak yang mengikuti kegiatan bermain konstruktif antara kelompok eksperimen dan kelompok kontrol, dimana hasil menunjukkanbahwa kecedasan interpersonal dengan kegiatan bermain konstruktif anak kelompok eksprimen lebih tinggi dari anak yang bermain konstruktif untuk kelompok kontrol.

\section{SIMPULAN}

Kemampuan kecerdasan interpersonal anak yang berada pada kelompok eksperimen dalam bermain konstruktif, rata-rata pemenuhan indikator kecerdasan interpersonal berada pada kategori tinggi, sedangkan anak yang berada pada kelompok kontrol dalam kegiatan bermain konstruktif, menunjuk nilai dengan rata-rata pemenuhan indikator kecerdasan interpersonal berada pada kategori sedang, dan untuk uji statistik menunjukkan bahwa terdapat pengaruh antara kegiatan bermain konstruktif terhadap kecerdasan interpersonal anak di Taman Kanak-kanak.

\section{UCAPAN TERIMA KASIH}

Kami mengucapkan terima kasih kepada kepala sekolah, guru dan orang tua anak didik pada TK yang mejadi subjek dari penelitian yang berlokasi di Kabupaten Gowa atas dukungan dan partisipasinya selama dalam pelaksanaan penelitian.

\section{DAFTAR PUSTAKA}

Abas, M., Solihatin, E., \& Nadiroh. (2019). Effect of instructional models and interpersonal intelligence on the social studies learning outcomes. International Journal of Instruction, 12(4), 705-718. https:/ / doi.org/10.29333/iji.2019.12445a

Agustin, M., Inten, D. N., Permatasari, A. N., \& Mulyani, D. (2021). Strategi Guru PAUD dalam Mengembangkan Kecerdasan Interpersonal Anak Usia Dini di Saat Belajar dari Rumah. Jurnal Obsesi: Jurnal Pendidikan Anak Usia Dini, 5(2), 1997-2007. https://doi.org/10.31004/obsesi.v5i2.1055

Amirova, B. (2020). Study of nis teachers' perceptions of teacher professionalism in $\begin{array}{llll}\text { Kazakhstan. IAFOR Journal of } & \text { 7-23. }\end{array}$ https:// doi.org/10.22492/ije.8.4.01

Aouani, H., Slimani, M., Bragazzi, N. L., Hamrouni, S., \& Elloumi, M. (2019). A preliminary validation of the arabic version of the "profile of emotional competence" questionnaire among tunisian adolescent athletes and nonathletes: Insights and implications for sports psychology. Psychology Research and Behavior Management, 12, 155-167. https:// doi.org/10.2147/PRBM.S188481

Bachtiar, M. Y. (2017). Pengaruh Bermain Peran Terhadap Kecerdasan Interpersonal Pada Anak Kelas A di Taman Kanak-Kanak Buah Hati Kota Makassar. AWLADY : Jurnal Pendidikan Anak, 3(2), 139. https:/ / doi.org/10.24235/awlady.v3i2.1618

Bailey, R., Raisch, N., Temko, S., Titus, B., Bautista, J., Eniola, T. O., \& Jones, S. M. (2021). Innovations in social and emotional learning research and practice: building from evidence and applying behavioral insights to the design of a social and emotional learning intervention in northeast Nigeria. International Journal of Environmental Research and Public Health, 18(14), 7397. https:// doi.org/10.3390/ijerph18147397

Ching, Y. H., \& Hsu, Y. C. (2016). Learners' interpersonal beliefs and generated feedback in an online role-playing peer-feedback activity: An exploratory study. International Review of Research in Open and Distance Learning, 17(2), 105-122. https:// doi.org/10.19173/irrodl.v17i2.2221 
Damayanti, R. R., CH, M., \& Hapidin, H. (2018). Pengaruh Bermain Peran Mikro terhadap Kecerdasan Interpersonal. Jurnal Obsesi : Jurnal Pendidikan Anak Usia Dini, 2(1), 34. https://doi.org/10.31004/obsesi.v2i1.5

Dewi, Dian Puspa, Fachrurrazi, A., Istiana, Y., \& Yuyun Istiana. (2014). Konsep-Konsep Dasar Pendidikan Anak Usia Dini. Didaktika, Vol. 20 No. 2 Februari 2014, 5(1), 329-333. https://doi.org/10.1101/112268 https://doi.org/10.1101/112268

Fauziddin, M., Mayasari, D., \& Rizki, L. M. (2021). Effective Learning for Early Childhood during Global Pandemic. Al-Ishlah: Jurnal Pendidikan, 13(1). https://doi.org/10.35445/alishlah.v13i1.458

Fuller, E. A., \& Kaiser, A. P. (2020). The Effects of Early Intervention on Social Communication Outcomes for Children with Autism Spectrum Disorder: A Meta-analysis. Journal of Autism and Developmental Disorders, 50(5), 1683-1700. https://doi.org/10.1007/s10803-019-03927-z

Gan, Z. (2018). Success and failure in first-year teaching: Mainland Chinese ESL teachers in Hong Kong schools. Cogent Education, $4(1) . \quad 1$ https://doi.org/10.1080/2331186X.2018.1455631

Gardner, H. (2020). A Synthesizing Mind: A Memoir from the Creator of Multiple Intelligences Theory. In Ebook. https:// doi.org/10.7551/mitpress/12405.001.0001

Griffith, S. F., Hagan, M. B., Heymann, P., Heflin, B. H., \& Bagner, D. M. (2020). Apps as learning tools: A systematic review. In Pediatrics (Vol. 145, Issue 1, p. e20191579). https://doi.org/10.1542/peds.2019-1579

Klieba, A. I., Bludova, Y. O., Galushko, N. A., Pavlova, O. H., \& Pylypenko, N. V. (2020). Construction of an individual educational trajectory as a way to reveal the personal and professional potential of a future teacher. International Journal of Higher Education, 9(7), 73-83. https:/ / doi.org/10.5430/ijhe.v9n7p73

Klinkosz, W., Iskra, J., \& Artymiak, M. (2021). Interpersonal competences of students, their interpersonal relations, and emotional intelligence. Current Issues in Personality Psychology, 9(2), 125-134. https:// doi.org/10.5114/cipp.2021.105733

Machado, Y. S., Schubert, P. M. P., Da Silva Albuquerque, D., \& Kuhnen, A. (2016). Nature and children's play: Investigation of child-nature interaction in urban green parks. Temas Em Psicologia, 24(2), 669-680. https:// doi.org/10.9788/TP2016.2-14En

Masganti. (2021). Optimalisasi Kecerdasan Majemuk Anak Suai Dini dengan permainan trasisional. In Kencana. Kencana.

Meilanie, R. S. M. (2020). Survei Kemampuan Guru dan Orangtua dalam Stimulasi Dini Sensori pada Anak Usia Dini. Jurnal Obsesi : Jurnal Pendidikan Anak Usia Dini, 5(1), 958-964. https://doi.org/10.31004/obsesi.v5i1.741

Nikmah, S. M., \& Iswantiningtyas, V. (2020). Permainan Kopi ( Kotak Pintar ) Untuk Multiple Intelligence Anak. Prosiding Seminar Nasional Penalaran Dan Penelitian Nasional, $1(1), 228-239$.

Okwuduba, E. N., Nwosu, K. C., Okigbo, E. C., Samuel, N. N., \& Achugbu, C. (2021). Impact of intrapersonal and interpersonal emotional intelligence and self-directed learning on academic performance among pre-university science students. Heliyon, 7(3), e06611. https://doi.org/10.1016/j.heliyon.2021.e06611

Pahrul, Y., Hartati, S., \& Meilani, S. M. (2019). Peningkatan Kecerdasan Interpersonal melalui Kegiatan Menggambar pada Anak Usia Dini. Jurnal Obsesi : Jurnal Pendidikan Anak Usia Dini, 3(2), 461. https://doi.org/10.31004/obsesi.v3i2.186

Palunga, R., \& Marzuki. (2017). Peran Guru Dalam Pengembangan Karakter Peserta Didik di Sekolah Menengah Pertama Negeri 2 Depok Sleman. Pendidikan Karakter, Tahun VII, 109-123. https://doi.org/10.21831/jpk.v7i1.20858

Pirrone, C., Nicolosi, A., Passanisi, A., \& Di Nuovo, S. (2015). Learning potential in mathematics through imagination and manipulation of building blocks. 
Mediterranean Journal of Social Sciences, 6(4S3), 152-159. https:// doi.org/10.5901/mjss.2015.v6n4s3p152

Rodman, A. M., Jenness, J. L., Weissman, D. G., Pine, D. S., \& McLaughlin, K. A. (2019). Neurobiological Markers of Resilience to Depression Following Childhood Maltreatment: The Role of Neural Circuits Supporting the Cognitive Control of Emotion. Biological Psychiatry, 86(6), 464-473. https://doi.org/10.1016/j.biopsych.2019.04.033

Supli, A. A., Yu Ping, H., Omar, N. L. B., \& Yun Yi, W. (2021). Research strategy: A constructive play for anatomy learning system based on human finger gestures on holographic display. Annals of Emerging Technologies in Computing, 5(Special issue 5), 120-128. https:// doi.org/10.33166/AETiC.2021.05.015

Tariq, A., Beihai, T., Ali, S., Abbas, N., \& Ilyas, A. (2019). Mediating effect of cognitive social capital on the relationship between physical disability and depression in elderly people of rural Pakistan. International Journal of Environmental Research and Public Health, 16(21), 4232. https://doi.org/10.3390/ijerph16214232

Ubago-Jiménez, J. L., Zurita-Ortega, F., Román-Mata, S. S., Puertas-Molero, P., \& GonzálezValero, G. (2020). Impact of physical activity practice and adherence to the mediterranean diet in relation to multiple intelligences among university students. Nutrients, 12(9), 1-12. https:// doi.org/10.3390/nu12092630

van Hoorn, J., McCormick, E. M., \& Telzer, E. H. (2018). Moderate social sensitivity in a risky context supports adaptive decision making in adolescence: Evidence from brain and behavior. Social Cognitive and Affective Neuroscience, 13(5), 546-556. https:// doi.org/10.1093/scan/nsy016

Vaquero-Solís, M., Amado Alonso, D., Sánchez-Oliva, D., Sánchez-Miguel, P. A., \& IglesiasGallego, D. (2020). Emotional intelligence in adolescence: Motivation and physical activity. Revista Internacional de Medicina y Ciencias de La Actividad Fisica y Del Deporte, 20(77), 119-131. https:// doi.org/10.15366/rimcafd2020.77.008

Wulandari, A., \& Bachtiar, M. Y. (2021). Peningkatan Kemampuan Motorik Halus Anak Melalui Penggunaan Permainan Konstruktif pada Taman Kanak-Kanak. TEMATIK: Jurnal Pemikiran Dan Penelitian Pendidikan Anak Usia Dini, 5(1), 7. https://doi.org/10.26858/tematik.v5i1.19708 